\title{
Evaluation of Aerosol Jet Printing (AJP) technology for electronic packaging and interconnect technique
}

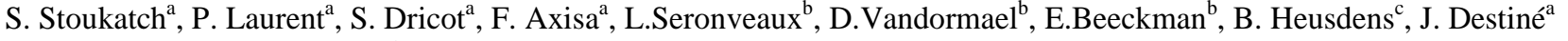 \\ ${ }^{a}$ EMMI/Microsys, University of Liège, 4000 Liège, Belgium \\ Tel: +32(0)4 24662 55, E-mail: serguei.stoukatch@ulg.ac.be \\ ${ }^{\mathrm{b}}$ SIRRIS, Collective Centre of the Belgium Technology Industry, 4102, Liege Science park, Belgium \\ ${ }^{\mathrm{c}}$ TAIPRO Engineering, Rue du Bois Saint Jean, 15/17, 4102 Seraing, Belgium
}

\begin{abstract}
We evaluated suitability of AJP (Aerosol Jet Printing) deposited silver layer on variety of organic substrates for the most common interconnect techniques used for electronic packaging. Specifically, we checked if the AJP silver layer can be electrically interconnected by $\mathrm{Au}$ and $\mathrm{Al}$ wires bonding technique. We also evaluated suitability of AJP silver layer for surface-mount technology (SMT). We performed electrical characterization of the AJP silver layer. We realized a fully functional working prototype of Autonomous Wireless Sensor Node system using AJP silver conductive track as an electrical interconnection.
\end{abstract}

\section{Introduction}

Aerosol Jet Printing (AJP) is an innovative technology for a selective maskless deposition of wide range of materials (conductive, dielectric, biological, nanoparticles etc.) at micron-scale (minimum features of $10 \mu \mathrm{m}$ line and $10 \mu \mathrm{m}$ space are achieved). Because it is a contactless technology, it suits for application on any flat and non-flat, flexible and rigid substrates, and moreover for complex 3D systems. The technology is particularly unique for deposition of a conductive silver paste on plastic substrates. It is known that the organic substrates are particularly sensitive to thermal treatment, as a maximum temperature and time of thermal exposure. AJP silver layer has very low sintering temperature, as low as $100-150^{\circ} \mathrm{C}$. The AJP silver layer fine pattern of $10 \mu \mathrm{m}$ line and $10 \mu \mathrm{m}$ space features is reportedly achieved [15].

That result is much better than a pattern realized by stateof-art a conventional screen printing technology there 100$150 \mu \mathrm{m}$ is an absolute minimum value of line/space features, and it is still better than a $30 \mu \mathrm{m}$ smallest features achieved by inkjet printing [6]. Remarkably, the conventional screen printing and inkjet printing technology are not suitable for 3D application.

Despite the advantages listed above the AJP technology remains still a novel technology there number issues must be studied and the technology is not yet widely accepted by industry.

\section{AJP deposition}

We evaluated set of different samples there AJP silver pattern have been deposited using Optomec AJ300CE system. Sirris our research partner in the ongoing project is developing AJP silver deposition process. There are several commercially available silver inks that are suitable for AJP deposition; among them we selected the most common CSD32 silver nano-dispersion, manufactured by Cabot. The ink viscosity is $100 \mathrm{mPa} . \mathrm{s}$. The CSD-32 silver ink comprises of engineered nanoparticles of $60 \mathrm{~nm}$ dimensions, and 45-50\% weight in a liquid vehicle (glycol based solvent) [7].

During the deposition process the ink is supplied by the system into pneumatic activation mode by dry nitrogen (carrier and sheath gas). The ink has been deposited on the substrates and sequentially sintered by a laser. The laser of $100 \mathrm{~mW}$ power and $532 \mathrm{~nm}$ wavelength generated $10 \mu \mathrm{m}$ spot on freshly deposited silver layer. It requires only $100 \mu$ s dwell tile to sinter the silver ink. Such short time of thermal exposure allows the thermal sintering on silver nano-ink, meanwhile the thermal sensitive plastic substrates remains at low temperature. The ink's manufacture recommends to perform sintering by mass curing process, there the ink and the substrate are subjected to temperature of $150^{\circ} \mathrm{C}$ for $30 \mathrm{~min}$. Sirris has been developed the sintering process there only the deposited ink is exposure to high temperature (estimated $100^{\circ} \mathrm{C}$ [8]) and the thermal sensitive plastic substrate remains at low temperature (below $80^{\circ} \mathrm{C}$ ).

Once the silver pattern is sintered, it has been characterized using PLuNeox 3D optical profilometer. The example of topological characterization presented below on Fig.1.

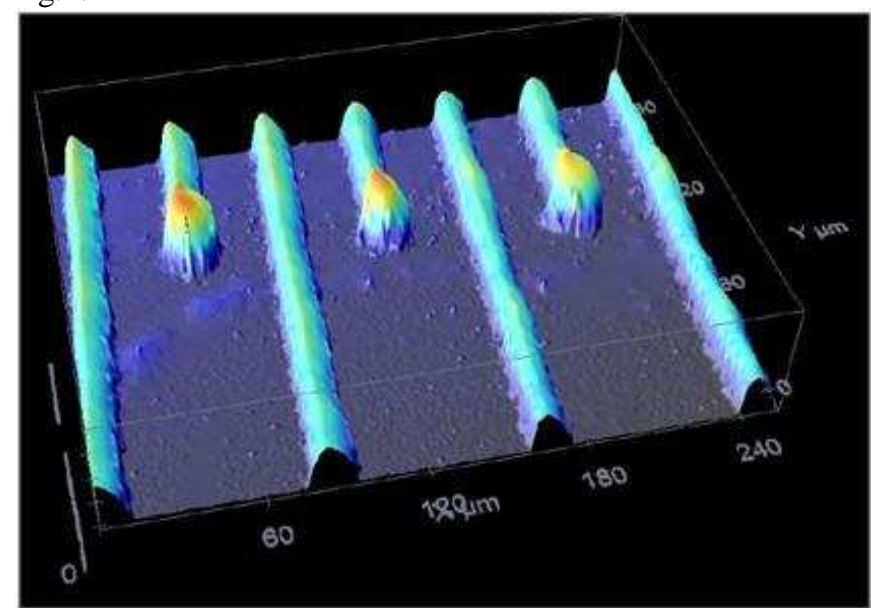

Figure 1: Silver line of $20 \mu \mathrm{m}$ width printed on a glass substrate.

\section{Wire bonding evaluation}

For our investigation, the silver layer is deposited by AJP on following organic substrates: PI (polyimide, from DuPont trademark: Kapton) of $25 \mu \mathrm{m}$ thickness, FR4 of $1.6 \mathrm{~mm}$ thickness, $1 \mathrm{~mm}$ thick injected polycarbonate (PC) and $1 \mathrm{~mm}$ thick injected acrylonitrile butadiene styrene (ABS). Some material such PI and FR4 are in widely used and become 
conventional material as a board or as a carrier for the electronic assembly. Other material such PC and ABS are still less known for that. In the table 1 for your reference we listed the most important for the assembly mechanical and thermal properties of the organic substrates.

Table 1: Mechanical and thermal properties [10].

\begin{tabular}{|l|l|l|l|l|}
\hline Material & $\begin{array}{l}\mathrm{Tg}, \\
{ }^{\circ} \mathrm{C}\end{array}$ & $\begin{array}{l}\text { Operating } \\
\text { temperature, }{ }^{\circ} \mathrm{C}\end{array}$ & $\begin{array}{l}\text { CTE, }{ }^{\circ} \\
\mathrm{C} / \mathrm{ppm}\end{array}$ & $\begin{array}{l}\text { E-modulus, } \\
\text { GPa }\end{array}$ \\
\hline FR4 & 150 & $-55 \ldots+125$ & $14 / 70$ & 24 \\
\hline PI & 260 & $-80 \ldots+210$ & $20 /$ n.a. & 2.5 \\
\hline PC & 150 & $-40 \ldots+130$ & $65 /$ n.a. & $2.0-2.4$ \\
\hline ABS & 105 & $-20 \ldots+80$ & 56/n.a. & 2.3 \\
\hline
\end{tabular}

After fabrication the test samples, we assessed suitability of AJP deposited silver layer on 4 organic substrates in terms of different conventional interconnect techniques used for the electronic packaging[9] . Specifically, we checked if the AJP silver layer can be electrically interconnected by $\mathrm{Au}$ and $\mathrm{Al}$ wires bonding technique. We evaluated FR4, PI, PC and ABS substrates in terms of $\mathrm{Au}$ and $\mathrm{Al}$ wire bonding. Apparently the wire bonding on AJP deposited silver layer has limited bondability and a status as on the date of preparing the paper that the manufactured configuration can't be used for mass scale production. We tried to bond $\mathrm{Au}$ wire at $150^{\circ} \mathrm{C}, 120^{\circ} \mathrm{C}$, $80^{\circ} \mathrm{C}$ and at room temperature to FR4 and PI substrate. For $\mathrm{PC}$ and $\mathrm{ABS}$ because its lower $\mathrm{Tg}$, we used $80^{\circ} \mathrm{C}$ and at room temperature wire bonding. We also tried $\mathrm{Al}$ wire bonding (room temperature process) on FR4, PI, PC and ABS substrates. We observed several typical wire bonding failures: a wire bonding imprint and a metal delamination.

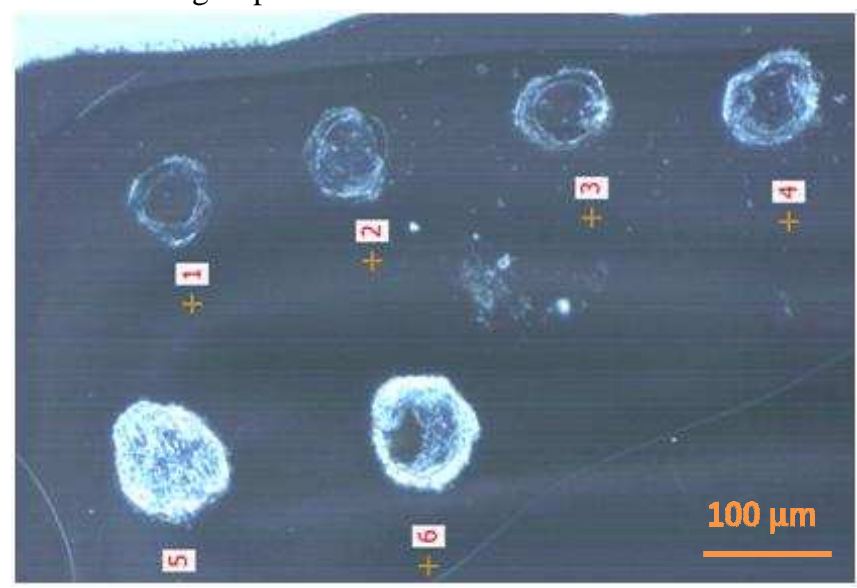

Figure 2: Au wire bonding imprint on surface of AJP silver layer deposited on ABS substrate.

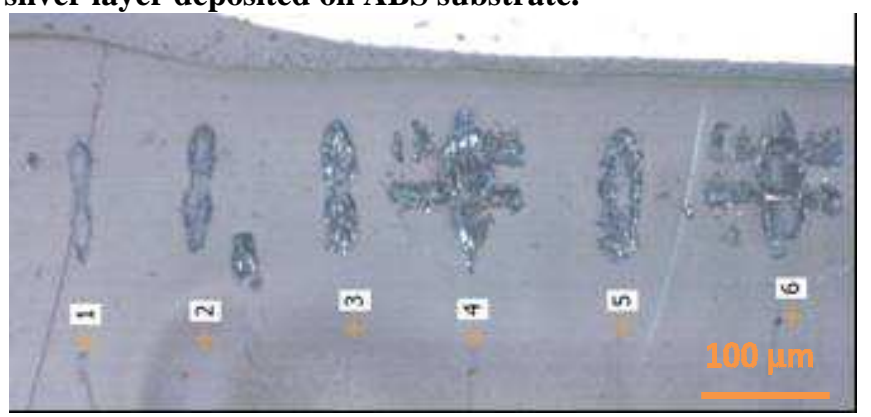

Figure 3: Al wire bonding imprint on surface of AJP silver layer deposited on PC substrate.
There are number reasons that can cause a limited bondability for $\mathrm{Au}$ and $\mathrm{Al}$ wires. The silver AJP deposited layer has a relatively poor adhesion to the organic material underneath. The failure mode observed such bond pad peel suggests a poor adhesion of AJP layer to the carrier. The adhesion can be generally improved by adding the adhesion layer. We are also investigating the alternative cure conditions that we believed can improve that. Generally speaking, the wire bonding is more difficult on the plastic substrates; the plastic substrates are usually much softer or at least softer than the rigid substrates that are conventionally used for the wire bonding. An example of such material and substrates is as following: $\mathrm{Si}, \mathrm{SiO} 2, \mathrm{SiN}, \mathrm{SiON}$ and $\mathrm{Al}, \mathrm{Au}, \mathrm{Ni}$. E-modules of the rigid substrate is above than $100 \mathrm{GPa}$, versus FR4 is $30 \mathrm{GPa}$ and other tested materials as PI, PC, ABS have less than $3 \mathrm{GPa}$.

Based on the bonding trials we could not find a real problem of non-bondability, on one side the organic low Emodulus substrate causes the bondability issue and on another side we did not succeed to weld the wire bonds to the AJP deposited silver track even on harder substrate as FR4. The FR4 substrate normally suits for both, for $\mathrm{Al}$ and $\mathrm{Au}$ wedge wire bonding techniques.

The wire bonding on AJP deposited silver layer has limited bondability in terms of $\mathrm{Au}$ and $\mathrm{Al}$ wire bonding. We consider that fact as definitely not a drawback for the AJP technology; because of the idea to introduce the AJP silver conductive track as an alternative technique for the conventional interconnect technology, specifically for the wire bonding.

\section{SMT evaluation}

On all 4 plastic substrates: FR4, PI, PC and ABS we also evaluated suitability of AJP silver layer for surface-mount technology (SMT). The layout of the test substrate is depicted on figure 4. Each substrate comrises a matrix of 30 SMD footprints suitable for 0402 components placement.

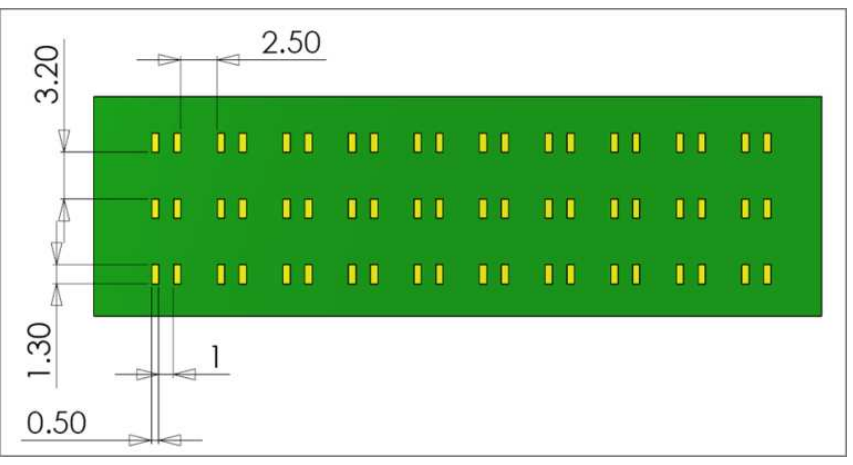

Figure 4: Layout of the test substrate for SMT evaluation. All dimensions are in $\mathbf{~ m m}$.

For that we tried two the most common SMT techniques, namely a reflow soldering and a conductive adhesive. As a pick and place tool for mounting components we used the automatic SMT pick and place system from Autotronik (Model: BS384V1). The system performs high accuracy mounting variety of SMT components as following: 01005, 0201, 0402, 0603, SOIC, PLCC, BGA, $\mu$ BGA, CSP, QFP etc. 
at placement rate up to $4000 \mathrm{UPH}$. Additionally to that, the system has a high precision dispensing system (suitable for solder and adhesives), bottom vision alignment system and can perform vision inspection before and after production. For the evaluation we used dummy SMD 0402 components.

We started the evaluation with a conductive isotropic adhesive. We investigated two curing schedule that differs by cure temperature and cure time: $3 \mathrm{~h}$ at $80^{\circ} \mathrm{C}$ and $15 \mathrm{~min}$ at $120^{\circ} \mathrm{C}$. We placed SMD components on $\mathrm{PC}$ and $\mathrm{ABS}$ substrates and cured at $80^{\circ} \mathrm{C}$ and $120^{\circ} \mathrm{C}$ for $\mathrm{PC}$ and $80^{\circ} \mathrm{C}$ for ABS. Additionally for the adhesive method we evaluated soldering technique on higher $\mathrm{Tg}$ substrates as FR4 and PI. For the soldering we chosen conventional lead-free solder (melting point of $218^{\circ} \mathrm{C}$ and reflow temperature of $240^{\circ} \mathrm{C}$ ). The soldering was not evaluated on lower Tg substrates as PC and ABS.

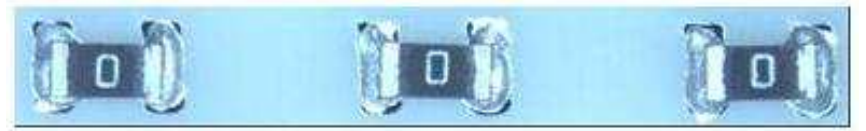

Figure 5: The SMD mounted on ABS with adhesive cured at $80^{\circ} \mathrm{C}$.

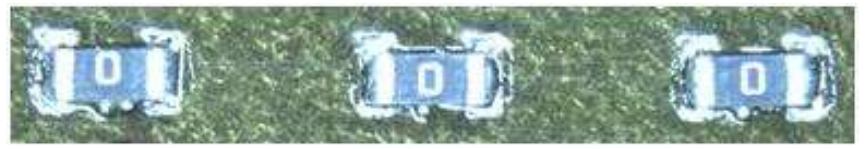

Figure 6: The SMD mounted on PI with lead-free solder.

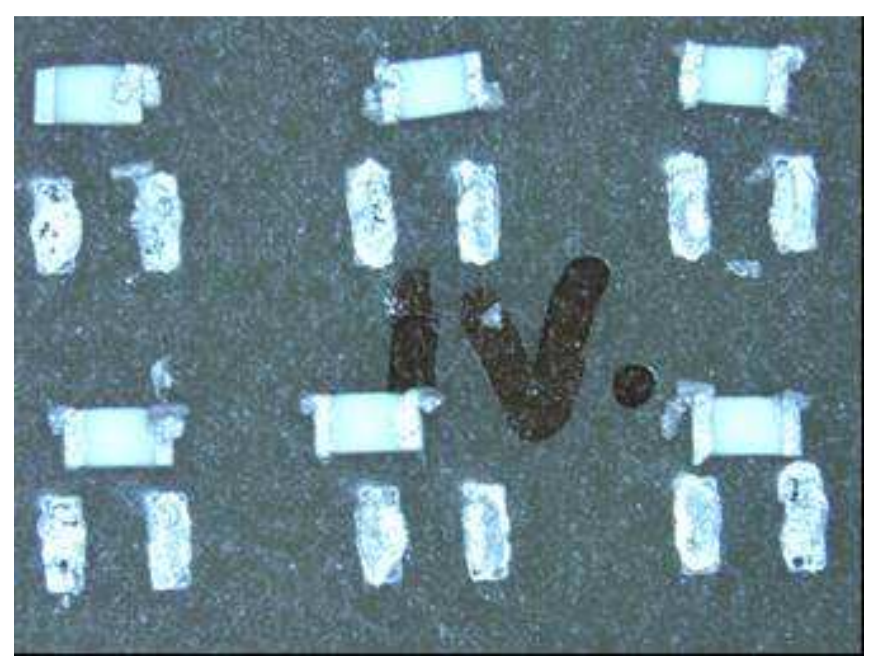

Figure 7: Typical observation of shear mode (SMD on FR4 attached by conductive glue and sheared).

The assembly has been inspected visually and evaluated by shear test and sequentially the failure mode for the shear test has been observed and characterized. The value for the shear test is in line with the results normally obtained on the rigid substrate with conventional finish and meets SMT specification. AJP deposited silver layer on all evaluated substrates (PI, FR4, PC and ABS) are suitable for surfacemount technology using conductive adhesive, and PI and FR4 are suitable for soldering technique.

\section{D Printed Electronics}

Microsys laboratory realized a fully functional prototype of Autonomous Wireless Sensor Node. The system has unlimited autonomy because of energy harvesting features achieved by using a photovoltaic solar cells. The version with solar cells has a total volume of $1.2 \mathrm{~cm} 3$ and extremely thin, the thickness is $2 \mathrm{~mm}$. The system is suitable for operation in standard ambient environment. As depicted on the figure 8, the system can be placed anywhere there is light present. The measurement rate is 2 units/min, working frequency is $868 \mathrm{MHz}$ and the system has extremely low power consumption of 100 microW. The working distance is $10 \mathrm{~m}$ indoor, and up to $100 \mathrm{~m}$ outdoor.

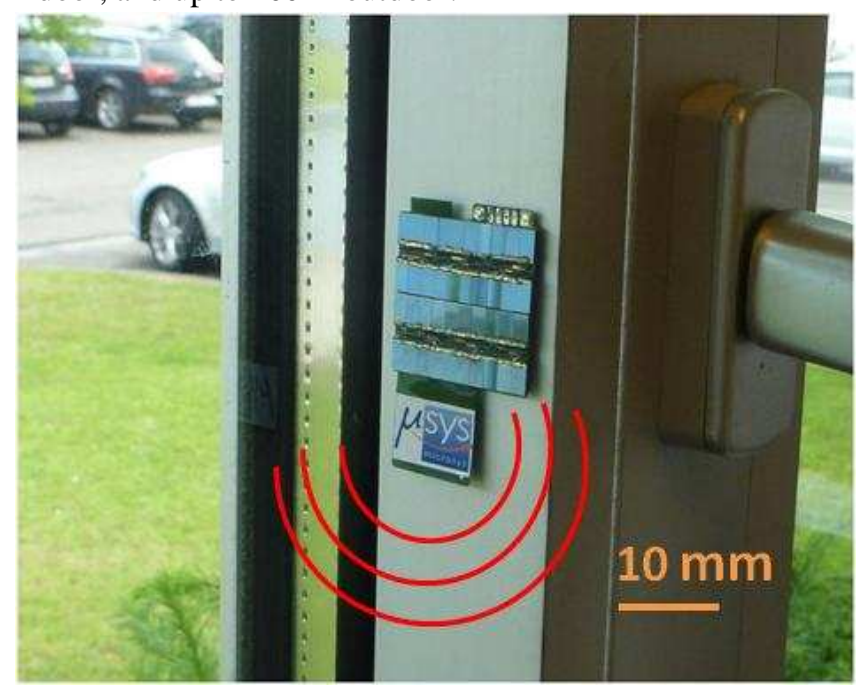

Figure 8: Fully functional prototype of Autonomous Wireless Sensor Node attached to the window frame.

For the assembly of the first working prototype we used conventional interconnect technology adopted for flexible plastic substrates. Because of severe constrains on thermal budget for the total system, we may not use Au wire bonding technique to create the interconnection between the flexible substrate and the PV cell. The $\mathrm{Au}$ wire bonding requires at least $150^{\circ} \mathrm{C}$ stage temperature that is much too high for our system. For the concept proof, we assembled the system using $\mathrm{Al}$ wire bonding (a room temperature process), however $\mathrm{Al}$ wire bonding has several constrains that prevent the method from use it for a high scale production. The welded wires then are sequentially encapsulated by UV curable encapsulant that is also a room temperature process. To explore an alternative method to the wire bonding in order to provide the electrical interconnection between the flexible substrate to the die, we used AJP silver ink. The AJP silver track was deposited and laser sintered. In order to obtain a continuous conductive track between the terminal of the substrate and the bond pad on the die, we needed to prepare the sample in a specific way. As depicted on the figure 10 , after the bonding the die to the substrate first we deposited a non-conductive fillet. The fillet has two main functions; first the fillet is to insulate the die side wall to prevent the die from the short circuit. The second function is to ensure the AJP silver track continuation. In principal the AJP track can be also deposited on the vertical wall, in our case on the die side wall, however it is more difficult to control the track thickness simultaneously both for 
the horizontal and vertical surfaces during the deposition process.

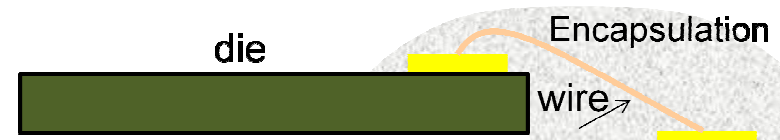

substrate

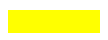

\section{Bond pad on the die and conductive} terminals on the substrate

\section{Die attach adhesive}

Figure 9: Cross-sectional schematic view of the interconnect: a conventional sequence using wire bonding and encapsulation.

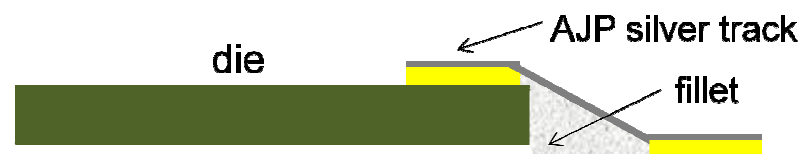

\section{substrate}

Figure 10: Cross-sectional schematic view on the interconnect: a realized by AJP silver layer.

For the fillet material we used UV curable die adhesive. The prototype realized by AJP silver layer as a result of replacement wire bond by AJP silver layer, has a lower profile compare to the first prototype assembled using the conventional packaging technique. The newest prototype is inheritably thinner, it this case we reduced the total assembly thickness by $0.5 \mathrm{~mm}$. Both prototypes have the same functionality. The figures 10 and 11 depict the interconnect area for both prototypes.

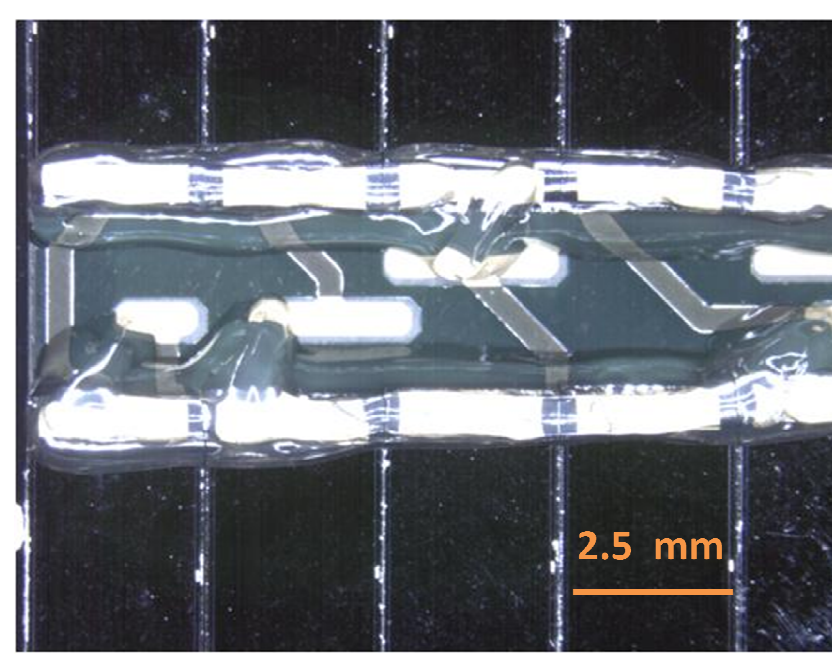

Figure 11: Image of the interconnect details between the substrate and the die, the interconnection realized using conventional packaging methods (wire bonding and encapsulation).

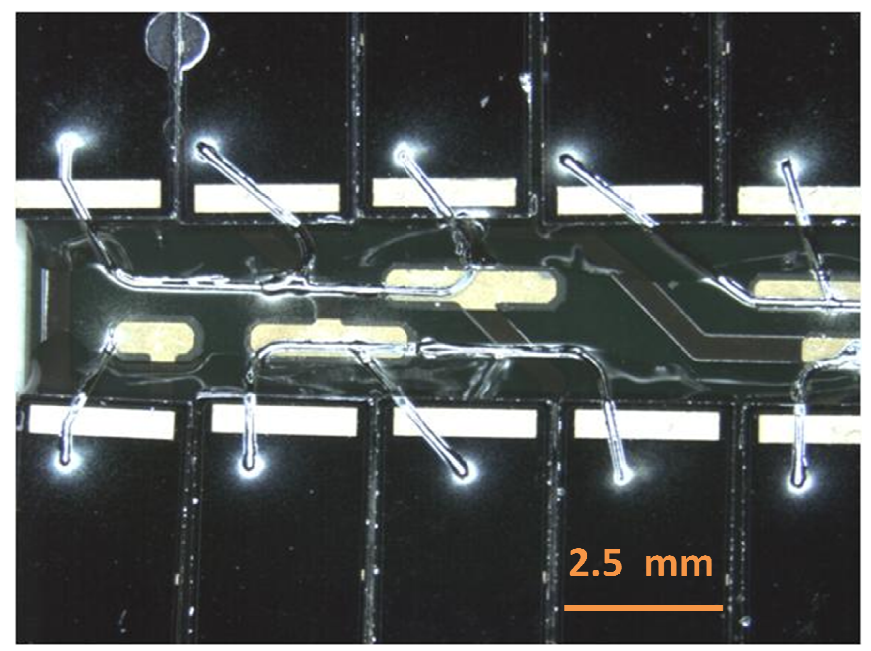

Figure 12: Image of the interconnect details between the substrate and the die, the interconnection realized by AJP silver layer.

\section{Electrical characterization}

We performed extensive electrical characterization of the AJP deposited silver track line $(60 \mu \mathrm{m}$ width, $3 \mu \mathrm{m}$ thickness and $20 \mathrm{~mm}$ length). For each lot of samples for the electrical measurements we selected randomly 3 samples.

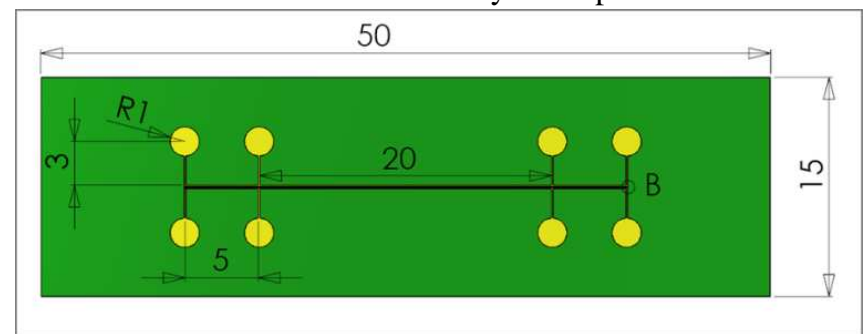

Figure 13: Layout of the test substrate for the electrical evaluation. All dimensions are in $\mathbf{~ m m}$.

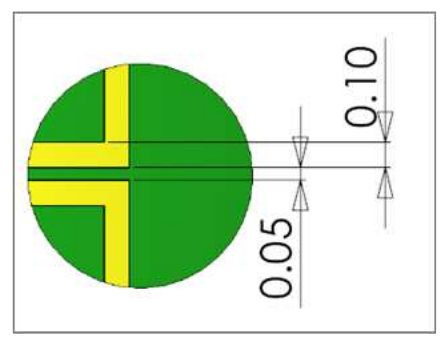

Figure 14: Details of the conductive track on the test substrate. All dimensions are in $\mathbf{m m}$.

We used 4 point measurement method and performed the electrical measurements on $\mathrm{DC}$, and $\mathrm{AC}$ at six following frequencies: $60 \mathrm{~Hz}, 1 \mathrm{kHz}, 10 \mathrm{kHz}, 100 \mathrm{kHz}, 1 \mathrm{MHz}$ and $2 \mathrm{MHz}$. Till the frequency of $100 \mathrm{kHz}$ the value of resistivity remains practically constant.

We compared the result of the electrical measurements with the manufacture (Cabot) datasheet. The lowest resistance value provided by Cabot for the CSD-32 nano-silver ink is in the range of $3-4 \mu \mathrm{Oh} * \mathrm{~cm}$ and can be achieved by sintering the samples at $250^{\circ} \mathrm{C}$ for $30 \mathrm{~min}$ [7]. According to the Cabot 30 $\mu \mathrm{Oh}^{*} \mathrm{~cm}$ is the best value for $150^{\circ} \mathrm{C}$ for $30 \mathrm{~min}$. 
The experimentally obtained value of the resistivity on our test samples is $16 \mu \mathrm{Oh}^{*} \mathrm{~cm}$, that is in 10 higher than the resistivity of bulk silver of $1.6 \mu \mathrm{Oh}^{*} \mathrm{~cm}$, however it is in line with resistivity of thin film silver tracks applied by other deposition methods and low enough to support many applications.

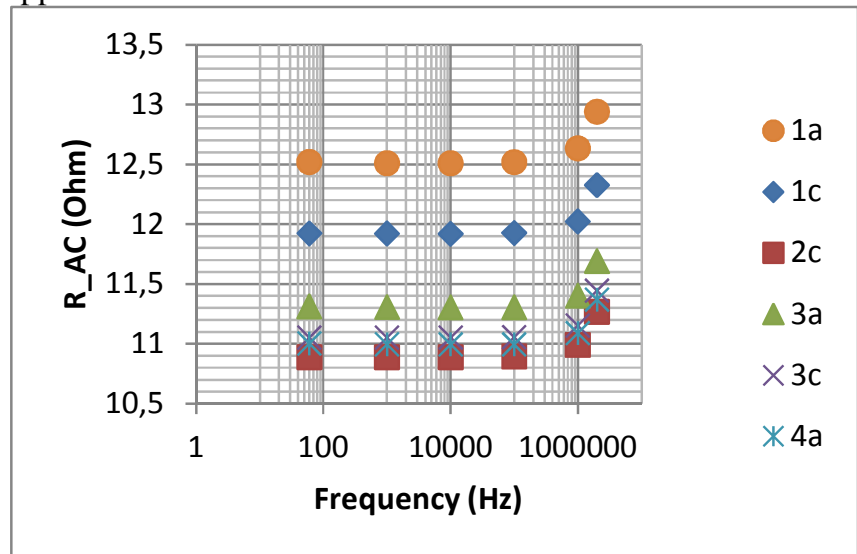

Figure 15: The resistance of AJP silver conductive track on ABS substrate of 6 samples.

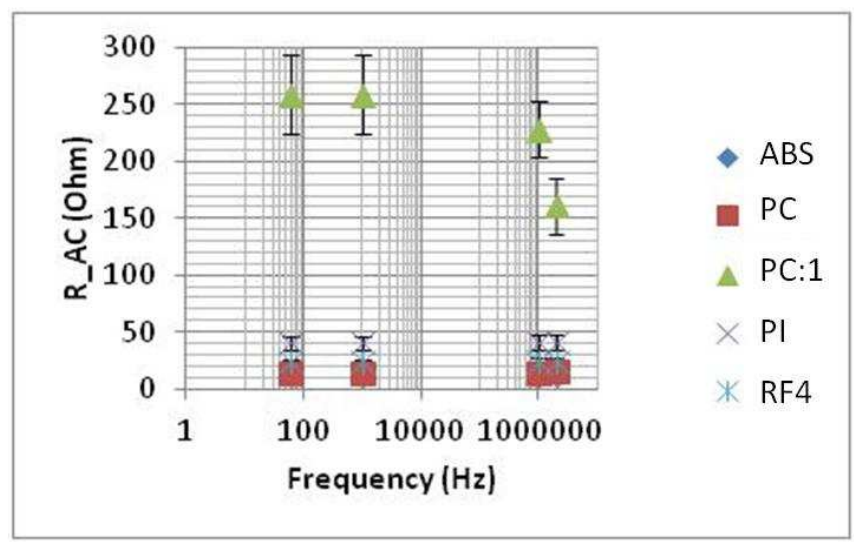

Figure 16: The resistance of AJP silver conductive track on ABS, PC, PC:1 (single layer), PI and FR4 substrates.

The figure 15 and 16 depict plots of electrical resistance versus frequency of the silver tracks processed on the organic substrates. On all substrates in study, except one: PC:1 (single layer of silver ink deposited on polycarbonate substrate, figure 16) we deposited sequentially 2 layers of AJP silver ink. We experimentally learnt that single-layer of silver ink deposition is not sufficient to form an even and continuous of silver ink track; remarkably that the substrates in study have different roughness and porosity that has direct effect on the silver track properties. The single layer silver track for the sample PC: 1 has the electrical resistivity from 5 to 10 time higher than 2 layers track.

\section{Conclusions}

Apparently the wire bonding on AJP deposited silver layer has limited bondability in terms of $\mathrm{Au}$ and $\mathrm{Al}$ wire bonding and a status as on the date of preparing the paper the AJP deposited silver layer can't be used for mass scale production. We consider that fact not as a drawback for the AJP technology, the AJP silver track as an alternative to the conventional interconnect technology, specifically for the wire bonding. AJP deposited silver layer on all evaluated substrates (PI, FR4, PC and ABS) are suitable for surfacemount technology using the conductive adhesive, and additionally to that AJP on PI and FR4 are suitable for soldering technique. The value of the resistivity is 16 $\mu \mathrm{Oh}^{*} \mathrm{~cm}$, that is higher than the resistivity of bulk silver of 1.6 $\mu \mathrm{Oh}^{*} \mathrm{~cm}$, however the value is in line with resistivity provided by the manufacture's datasheet, and similar as for thin film silver conductive tracks applied by other deposition methods. The resistivity is low enough to support many applications. We also demonstrated that for specific application (Autonomous Wireless Sensor Node prototype) the conventional interconnection technique as the wire bonding can be successfully replaced by AJP deposited conductive silver track.

\section{Acknowledgments}

The authors would like to acknowledge support from Microsys/ULG, Sirris and DICE/UCL. The research has been carried out in the frame of the Minatis project. The project is performed with the support of the Walloon Region of Belgium, European Union (FEDEX fund) and is carried out by a consortium of research institutions.

\section{References}

1. Martin Hedges, Mike Kardos, Bruce King, Mike Renn. Aerosol-Jet Printing for 3-D Interconnects, Flexible Substrates and Embedded Passives. Proceedings of the International Wafer Level Packaging Conference, San Jose, CA, November, 2006.

2. Matthias Hörteis, Stefan W. Glunz. Fine Line Printed Silicon Solar Cells Exceeding 20\% Efficiency: Progress in Photovoltaics: Research and Applications 2008; 16:555-560.

3. Bruce King, Mike Renn. Aerosol Jet ${ }^{\circledR}$ direct write printing for mil-aero electronic applications, published on www.optomec.com

4. Martin Hedges, Aaron Borras Marin 3D Aerosol Jet ${ }^{\circledR}$ Printing - Adding Electronics Functionality to RP/RM Presented at DDMC 2012 Conference, March 14-15, 2012, Germany, Berlin.

5. W. Verheecke etc, Optimization Aerosol Jet Printing of silver interconnects on polyimide film for embedded electronics applications, $8^{\text {th }}$ International DAAAM Baltic Conference "Inductrial Engineering", 19_21 April 2012, Tallinn, Estonia, in Conf. Proc. pp.373-379.

6. "Nanotechnologies and Electronics Packaging" by James E. Morris, 2008

7. Datasheet CSD-32, Cabot printed Electronics Materials.

8. D.Vandormael et al., "Direct deposition of surface acoustic wave sensors by aerosol jet printing technique", in Proc. Smart Systems Integration (SSI) Conf., Zurich, Switzerland, March 21-22, 2011.paper 32

9. G.Harman "Wire Bonding in Microelectronics: Materials, Processes, Reliability, and Yield", McGraw-Hill Professional; 3d edition, 2010. 290p.

10. www.engineeringtoolbox.com (material properties). 